Research Article

\title{
Social Responsibility Decision-Making of Universities in Stackelberg Competition
}

\author{
Xiaolei Wang $\mathbb{D},{ }^{1}$ Chaoqun Sun $\mathbb{D}^{2},{ }^{2}$ and Jiali Liu $\mathbb{D}^{3,4}$ \\ ${ }^{1}$ School of Control Engineering, Northeastern University at Qinhuangdao, Qinhuangdao 066004, China \\ ${ }^{2}$ School of Economics, Northeastern University at Qinhuangdao, Qinhuangdao 066004, China \\ ${ }^{3}$ Center for China Public Sector Economy Research of KRI, Jilin University, Changchun 130012, China \\ ${ }^{4}$ School of Economics, Jilin University, Changchun 130012, China \\ Correspondence should be addressed to Jiali Liu; liujiali@jlu.edu.cn
}

Received 6 July 2021; Accepted 23 July 2021; Published 9 August 2021

Academic Editor: Daqing Gong

Copyright $\odot 2021$ Xiaolei Wang et al. This is an open access article distributed under the Creative Commons Attribution License, which permits unrestricted use, distribution, and reproduction in any medium, provided the original work is properly cited.

\begin{abstract}
This paper establishes a Stackelberg competition model of two universities considering social responsibility (SR) and market sensitivity (MS) and examines the equilibrium results of four different scenarios: only the leader implements SR; only the follower implements SR; both the leader and the follower implement SR; neither the leader nor the follower implements SR. Then, a comparative analysis is carried out on the influence of MS and SR level. The results show that the influence of MS depends on SR implementation instead of competitive position. If MS is sufficiently high, two universities have the motive to implement more SR; under different competition scenarios, universities make different SR decisions, but the leader and the government make the same decisions on the optimal SR level. Therefore, the government could encourage the leader to take SR first.
\end{abstract}

\section{Introduction}

With the emergence of various economic, social, and ecological problems, social responsibility (SR) has attracted more and more attention. Many universities try to establish competitive advantages and improve reputation through the implementation of SR. By implementing SR, universities can contribute to the community and economic development and create opportunities for their development in the long term $[1-3]$. Therefore, universities are willing to provide better services and even promote international development [4]. Then, several issues are worthy of further exploration: what are the conditions for universities to implement SR? What is the optimal SR level for universities to pursue their interests? What role does the market play in the SR implementation by universities?

There is abundant literature on universities and SR, which means serving society and being responsible for society. Under the premise of high quality and fairness, universities should actively cooperate in serving public interests [5]. Boelen and Woollard [6, 7] studied the adjustments and strategic consensuses of universities implementing SR. And they paid attention to reputation and satisfaction of consumer needs in their research. Moon and Orlitzky [8] found that the reputation of universities is correlated with the educational plans and measures for sustainability. They all provide support for the price function setting of this paper. Nejati et al. [9] investigated whether world-class universities pay attention to SR, and analyzed the degree of their SR implementation. Therefore, this article also explores the level of SR. Dima et al. [10] derived the academic SR from the SR of universities and established a six-dimensional model for university SR. They only pay attention to the measurement of social responsibility and do not further explore the influencing factors of social responsibility. Garde-Sánchez et al. [11] found that SR does not greatly contribute to the positional or competitive advantages of universities, but incorporating SR in teaching and research can enhance social welfare. They believe that SR has not been used as a differentiating factor in the pursuit of position or competitive advantage, but this paper explores the behavior and degree of social responsibility of universities from the 
perspective of competitive position. Latif [12] segmented university SR and confirmed that universities can enhance public security and happiness. They explored the positive impact of social responsibility on society, which provided a realistic basis for the setting of the utility function. Ventres et al. [13] believed that universities can turn awareness into behavior, thereby improving the educational performance of individuals and their families. They focused on the discussion on the formulation and implementation of social responsibilities and paid attention to the important role of social responsibilities in the identification of universities. Aleixo et al. [14] demonstrated that $11 \%$ of all universities actively participate in sustainable development practice, but most universities have not paid enough effort. Compared with this literature, we incorporate consumers and the government into decision-making to reflect the concerns of different stakeholders and emphasize the joint roles of the market and the government. Hayter and Cahoy [15] carried out a strategic SR framework analysis on the social influence of universities and stressed the importance of dynamic updates and strategic coordination. They highlighted the strategic social responsibility behavior of universities, which is also a key content of this paper. Galvao et al. [16] investigated the factors affecting students' SR orientation in higher education and encourage the addition of SR orientation to higher education programs. Ayala-Rodríguez et al. [17] verified whether social awareness affects the SR implementation by universities, pointing out that a growing number of stakeholders expect universities to implement SR [18]. Students are important stakeholders of universities, and their increased sensitivity to social responsibilities is conducive to promoting universities to implement social responsibilities. Symaco and Tee [19] discussed the important effect of universities on SR and sustainable development and introduced the role of universities in local development. Binsawad [20] measured the influence of SR over the competitiveness of universities and learn that SR implementation can enhance competitiveness. This is also the reason for the adoption of Stackelberg model to explore social responsibility of universities. Whether social responsibility can bring competitive advantages to universities and whether such advantages are affected by their competitive position are significant questions we try to answer. The abovementioned literature studies the relationship between universities and social responsibility from different perspectives, and notes the important role of the market and the government. This paper will analyze their relationship and impacts more comprehensively.

The main contributions of this paper are as follows: first, many scholars have investigated SR with competition models [21, 22], but few have combined SR level with universities; this paper constructs an oligopoly competition to examine how universities implement SR, laying the basis for their SR decision-making. Second, most studies assume that universities occupy the same competitive positions [23], while this research judges whether and how universities implement SR under a Stackelberg competition model. Our practice is more in line with the actual competition in the education market. The duopoly model is a common method for examining social responsibility and has been widely adopted. At present, few scholars have used the Stackelberg model to analyze university social responsibility. We enrich the existing literature in SR of universities. Third, few scholars have considered the influence of SR on market demand [24], which is prevalent in education market competition. This paper includes the effect of SR on market demand into the model and more effectively discloses how SR influences the education market. In this way, our research supports universities in making strategic SR decisions and facilitates the government's planning of education policies.

The rest of this paper is organized as follows. Section 2 constructs a Stackelberg competition model containing two universities. Section 3 analyzes the equilibrium results and examines the impacts of SR and MS on equilibrium results and makes comparisons. Section 4 puts forward the research conclusions and future direction.

\section{Model Construction}

Suppose there exists a duopoly model consisting of University 1 and University 2, who make decisions about whether to implement SR and the level of SR implementation through a Stackelberg competition around the output.

Hypothesis 1. There are four scenarios: only the leader implements SR; only the follower implements SR; both the leader and the follower implement SR; neither the leader nor the follower implements SR. The equilibrium results of the oligopoly competition in the four scenarios are indicated by subscripts LC, FC, CC, and NN, respectively. Based on the current design of anti-market demand function, this paper refers to the models of Liu et al. [25] and Chen et al. [26], considers the MS to SR, and assumes the inverse function as $p_{i}=b+r e-q_{i}-q_{j}, i \neq j, i, j=1,2$, where $r_{i} \in[0,1]$ is the SR level; $e>0$ is the MS to SR, which reflects the influence of SR on market price. The higher the $e$ value, the better the reputation of universities, the more recognized their products, and the higher the product price. Suppose University 1 is the leader, and University 2 is the follower. When only the leader implements SR, the inverse functions of the leader and the follower can be, respectively, described as $p_{1}=b+r e-q_{i}-q_{j}$, and $p_{2}=b-q_{i}-q_{j}$. When only the follower implements SR, the inverse functions of the leader and the follower can be, respectively, described as $p_{1}=b-q_{i}-q_{j}$, and $p_{2}=b+r e-q_{i}-q_{j}$. When neither the leader nor the follower implements SR, their inverse functions are $p_{i}=b-q_{i}-q_{j}, i \neq j, i, j=1,2$.

After SR is introduced to the utility functions, the utility of each university consists of profit $\left(\pi_{i}\right)$ and consumer welfare (cs): $U_{i}=\pi_{i}+\operatorname{rCS}[27,28]$. The profit function can be described as $\pi_{i}=p_{i} q_{i}-c q_{i}$, where $c$ is the marginal cost. When only the leader implements SR, the utility functions of the leader and the follower can be established as $U_{1}=\pi_{1}+$ rCS and $U_{2}=\pi_{2}$, respectively. When only the follower implements SR, the utility functions of the leader and the follower can be established as $U_{1}=\pi_{1}$ and $U_{2}=\pi_{2}+\mathrm{rCS}$, respectively. When neither the leader nor the follower 
implements SR, the utility functions of the two parties are $U_{i}=\pi_{i}$. The total social welfare can be defined as $\mathrm{SW}=\pi_{1}+\pi_{2}+\lambda \mathrm{CS}$, where $\mathrm{CS}=q_{1}^{2}+q_{2}^{2}+2 q_{1} q_{2} / 2 ; \lambda$ indicates the positive externality of social responsibility. The implementation of social responsibility by universities not only is beneficial to their own enrollment and cultivation of talents, but also has a positive impact on consumers and society.

Under the above assumptions, it is first considered that the SR level is exogenous and given. Then, the two universities carry out a Stackelberg competition and determine their optimal outputs under the principle of utility maximization. Next, the SR level is endogenous, and the optimal SR levels are determined by the universities for the maximal profit, or by the government for the maximal social welfare.

\section{Model Analysis}

3.1. Model LC. Suppose University 2 is a follower and adopts backwards induction to solve. In the second stage, by the principle of utility maximization, the output decision of the follower must satisfy $\partial U_{2}^{\mathrm{LC}} / \partial q_{2}=b-c-q_{1}-2 q_{2}=0$. Thus, the equilibrium output of the follower can be obtained as

$$
q_{2}^{\mathrm{LC}}=\frac{b-c-q_{1}}{2} .
$$

Substituting equation (1) into the utility function of the leader, in the first stage, the leader's output must satisfy $\partial U_{1}^{\mathrm{LC}} / \partial q_{1}=\left(b-c+4 e+q_{1}\right) r+2(b-c)-4 q_{1} / 4=0 \quad$ to maximize its utility. Thus, the equilibrium output of the leader can be obtained and is substituted to equation (1); the equilibrium outputs are

$$
q_{1}^{\mathrm{LC}}=\frac{2(b-c)+(b-c+4 e) r}{4-r}, q_{2}^{\mathrm{LC}}=\frac{b-c-(b-c+2 e) r}{4-r} .
$$

Since $q_{2}^{\mathrm{LC}} \geq 0$, the parameter ranges can be determined as $0<r \leq b-c / b-c+2 e$ and $0<e \leq(1-r)(b-c) / 2 r$.

Lemma 1. When only the leader implements $S R$, the equilibrium results are as follows:

$$
\begin{aligned}
\pi_{1}^{\mathrm{LC}} & =\frac{\left[b-c-(b-c-2 e) r-e r^{2}\right][(b-c+4 e) r+2(b-c)]}{(4-r)^{2}}, \pi_{2}^{\mathrm{LC}}=\frac{[(b-c+2 e) r-b+c]^{2}}{(4-r)^{2}}, \\
\mathrm{CS}^{\mathrm{LC}} & =\frac{(2 e r+3 b-3 c)^{2}}{2(4-r)^{2}}, \mathrm{SW}^{\mathrm{LC}}=\frac{-2 e(b-c+4 e) r^{3}+4 e^{2}(\lambda+6) r^{2}-2(b-c)[3(b-c)-2(3 \lambda+2) e] r+3(b-c)^{2}(3 \lambda+2)}{2(4-r)^{2}} .
\end{aligned}
$$

Proposition 1. (1) The effects of e:

$$
\frac{\partial q_{1}^{\mathrm{LC}}}{\partial e}>0, \frac{\partial p_{1}^{\mathrm{LC}}}{\partial e}>0, \frac{\partial \pi_{1}^{\mathrm{LC}}}{\partial e}>0, \frac{\partial q_{2}^{\mathrm{LC}}}{\partial e}<0, \frac{\partial p_{2}^{\mathrm{LC}}}{\partial e}<0, \frac{\partial \pi_{2}^{\mathrm{LC}}}{\partial e}<0, \frac{\partial \mathrm{CS}}{\partial e}>0, \text { and } \frac{\partial \mathrm{SW}}{\partial e}>0
$$

(2) The effects of $r$ : $\partial q_{1}^{L C} / \partial r>0$, if $0<e<3(b-c) /$ $r^{2}-8 r+8$, then, $\partial p_{1}^{L C} / \partial r<0$; if $3(b-c) / r^{2}-8 r$ $+8<e<(1-r)(b-c) / 2 r$, and then $\partial p_{1}^{L C} / \partial r>$ $0, \partial \pi_{1}^{L C} / \partial r>0, \partial q_{2}^{L C} / \partial r<0, \partial p_{2}^{L C} / \partial r<0 \partial \pi_{2}^{L C} / \partial r<0$ $\partial C S^{L C} / \partial r>0, \partial S W^{L C} / \partial r>0$.

\section{Proof. See Appendix A}

Proposition 1 shows that the output, price, and profit of University 1 are positively correlated with the MS $e$ to SR, and the consumer surplus and social welfare are also positively correlated with $e$, while the output, price, and profit of University 2 are negatively correlated with $e$. The reason is that University 1 gains a competitive position by implementing SR, which results in more benefits. For University 1 and the government, the growing market recognition of SR is conductive. They can cooperate in the cultivation of market sensitivity so that the entire market has a wider recognition of social responsibility, thus forcing University 2 to implement social responsibility.

The SR level $(r)$ also affects the equilibrium results. The output, price, and profit of University 1, as well as consumer surplus and social welfare, are positively correlated with $r$, but the output, price, and profit of University 2 are negatively correlated with $r$. The price of University 1 has a complex relationship with $r$. This relationship is related to $e$. Under a low $e$, the product price of University 1 decreases with the growing $r$. When $e$ surpasses a certain level, the price will increase with $r$. Therefore, only if the market is sufficiently sensitive to SR could universities increase their prices and profits by implementing more SR. Before SR implementation, universities should fully understand the market. For University 2, the follower who does not implement SR, a high SR level of University 1 is unfavorable. From the angle of the follower, it is wise to implement SR. 
3.2. Model FC. In the second stage, the output of University 2 needs to meet the first-order conditions $\partial U_{2}^{\mathrm{FC}} / \partial q_{2}=0$,

$$
q_{2}^{\mathrm{FC}}=\frac{e r+b-c-q_{1}}{2}
$$

By substituting equation (5) into the utility function of University 1, then we examine University 1's output decision. In the first stage, to satisfy $\partial U_{1}^{\mathrm{FC}} / \partial q_{1}=0$, the equilibrium outputs under Model FC can be derived as

$$
q_{1}^{\mathrm{FC}}=\frac{2(b-c)+(b-c-2 e) r+e r^{2}}{4-r}, q_{2}^{\mathrm{FC}}=\frac{b-c-(b-c-3 e) r-e r^{2}}{4-r} .
$$

Lemma 2. When only the follower implements $S R$, the equilibrium results are as follows:

$$
\begin{aligned}
\pi_{1}^{\mathrm{FC}} & =\frac{\left[2(b-c)-(b-c-2 e) r-e r^{2}\right][(b-c+e) r-(b-c)]}{(4-r)^{2}}, \pi_{2}^{\mathrm{FC}}=\frac{\left[e r^{2}+(b-c-3 e) r-b+c\right]^{2}}{(4-r)^{2}}, \\
\mathrm{CS}^{\mathrm{FC}} & =\frac{(e r+3 b-3 c)^{2}}{2(4-r)^{2}}, \mathrm{SW}^{\mathrm{FC}} \\
& =\frac{2 e^{2} r^{4}+2 e(b-c-7 e) r^{3}-4[-(\lambda+22)+12(b-c)] e r^{2}-2(b-c) r[3(b-c)-(3 \lambda+2) e] r+3(b-c)^{2}(3 \lambda+2)}{2(4-r)^{2}} .
\end{aligned}
$$

Since $q_{1}^{F C} \geq 0$ and $\pi_{1}^{F C} \geq 0$, the parameter ranges can be determined as $0<r \leq b-c / b-c+e$ and $0<e \leq(1-r)(b-c) / r$.
Proposition 2. (1) The effects of e:

$$
\frac{\partial q_{1}{ }^{F C}}{\partial e}<0, \frac{\partial p_{1}{ }^{F C}}{\partial e}<0, \frac{\partial \pi_{1}{ }^{F C}}{\partial e}<0, \frac{\partial q_{2}{ }^{F C}}{\partial e}>0, \frac{\partial p_{2}{ }^{F C}}{\partial e}>0, \frac{\partial \pi_{2}{ }^{F C}}{\partial e}>0, \frac{\partial C S^{F C}}{\partial e}>0, \text { and } \frac{\partial S W^{F C}}{\partial e}>0
$$

(2) The effects of $r$ :

$$
\begin{aligned}
& \text { If } 0<e<6(b-c)-\left(r^{2}-8 r+8\right) e /(4-r)^{2}, \partial q_{1}^{F C} / \partial r \\
& <0 \text {; if } 6(b-c)-\left(r^{2}-8 r+8\right) e /(4-r)^{2}<e< \\
& (1-r)(b-c) / r \text {, then } \partial q_{1}^{F C} / \partial r>0 ; \partial p_{1}^{F C} / \partial r<0 \text {, } \\
& \partial \pi_{1}^{F C} / \partial r<0, \text { if } 0<e<3(b-c) / r^{2}-8 r+12, \partial q_{2}^{F C} / \\
& \partial r<0 \text {; if } 3(b-c) / r^{2}-8 r+12<e<(1-r)(b-c) / r \text {, } \\
& \text { then } \partial q_{2}^{F C} / \partial r>0 \quad \text { if } 0<e<3(b-c) / r^{2}-8 r+ \\
& 12 \text {, then } \partial p_{2}^{F C} / \partial r<0 \text {; if } 3(b-c) \quad / r^{2}-8 r+8<e \\
& <(1-r)(b-c) / r \text {, then } \partial p_{2}^{F C} / \partial r>0 ; \text { if } 0<e<3(b- \\
& c) / r^{2}-8 r+12, \text { then } \partial \pi_{2}^{F C} / \partial r<0 ; \text { if } 3(b-c) / r^{2}-8 r+ \\
& 12<e<(1-r)(b-c) / r \text {, then } \partial \pi_{2}^{F C} / \partial r>0, \partial C S^{F C} \text {, } \\
& \partial r>0, \partial S W^{F C} / \partial r>0 .
\end{aligned}
$$

Proof. See Appendix B

Proposition 2 shows that the correlations of the outputs, prices, and profits of University 1 and University 2 with $e$ are opposite to those when only the leader implements SR. Therefore, the influence of $e$ depends on whether universities implement SR, rather than the competitive positions. The more sensitive the market is to SR, the higher the CS and SW. Increased market sensitivity is beneficial to followers, consumers, and society.

The price and profit of University 1 are negatively correlated with the SR level of University 2. Meanwhile, CS and SW remain positively correlated with the latter. With the growing SR level of University 2, the following terms first decrease and then increase the output, price, and profit of University 2, and the output of University 1 . Only if the market is highly sensitive $\left(3(b-c) / r^{2}-8 r+12\right.$ $<e<(1-r)(b-c) / r)$ do the output and price of University 2 increase with $r$, bringing more profit to that institution. Unlike when only the leader implements SR, both output and price are under the combined effect of market sensitivity and the SR level. Before SR implementation, the universities must measure $e$ and make reasonable strategic decisions. The increase of $e$ could make the universities more willing to improve their SR levels. For University 1, the leader who does not implement SR, the SR implementation by University 2 puts it in a weak position in the competition. In severe cases, the leader would earn less even if its output is on the rise. 
3.3. Model CC. Under Model CC, the output of University 2 satisfies $\partial U_{2}^{\mathrm{CC}} / \partial q_{2}=0$ in the second stage, and the output of
University 1 satisfies $\partial U_{1}^{\mathrm{CC}} / \partial q_{2}=0$ in the first stage. Finally, the equilibrium outputs can be described as

$$
q_{1}^{\mathrm{CC}}=\frac{(e r+b-c)\left(r^{2}-2 r+2\right)}{4-3 r}, q_{2}^{\mathrm{CC}}=\frac{-\left(r^{2}-r-1\right)(e r+b-c)}{4-3 r}
$$

Lemma 3. When both the leader and the follower implement

$S R$, the equilibrium results are as follows:

$$
\begin{aligned}
\pi_{1}^{\mathrm{CC}} & =\frac{(e r+b-c)^{2}\left(r^{2}-2 r+2\right)(2 r-1)}{(4-3 r)^{2}}, \pi_{2}^{\mathrm{CC}}=\frac{\left(r^{2}-r-1\right)(2 r-1)(e r+b-c)^{2}}{(4-3 r)^{2}} \\
\mathrm{CS}^{\mathrm{CC}} & =\frac{(e r+b-c)^{2}(r-3)^{2}}{2(4-3 r)^{2}}, \text { and SW }{ }^{\mathrm{CC}}=\frac{(e r+b-c)^{2}(r-3)[(\lambda+4) r-3 \lambda-2]}{2(4-3 r)^{2}}
\end{aligned}
$$

Since $\pi_{2}^{C C} \geq 0$, the ranges of $r$ can be determined as $0<r \leq 1 / 2$.

Proposition 3. (1) The effects of e:

$$
\frac{\partial q_{1}^{\mathrm{CC}}}{\partial e}>0, \frac{\partial p_{1}^{\mathrm{CC}}}{\partial e} \geq 0, \frac{\partial \pi_{1}^{\mathrm{CC}}}{\partial e} \geq 0, \frac{\partial q_{2}^{\mathrm{CC}}}{\partial e}>0, \frac{\partial p_{2}^{\mathrm{CC}}}{\partial e} \geq 0, \frac{\partial \pi_{2}^{\mathrm{CC}}}{\partial e} \geq 0, \frac{\partial \mathrm{CS}^{\mathrm{CC}}}{\partial e}>0 \text {, and } \frac{\partial S W^{\mathrm{CC}}}{\partial e}>0
$$

(2) The effects of $r$ :

If $0<r \leq 4-\sqrt{10} / 3$ and $0<e \leq\left(3 r^{2}-8 r+2\right)$ $(b-c) / 2\left(4-8 r+9 r^{2}-3 r^{3}\right)$, then $\partial q_{1}^{C C} / \partial r \leq 0$; if $0<r \leq 4-\sqrt{10} / 3$ and $0<e \leq\left(3 r^{2}-8 r+2\right)(b-c) /$ $2\left(4-8 r+9 r^{2}-3 r^{3}\right)$, then $\partial q_{1}^{C C} / \partial r>0$; if $4-\sqrt{10} / 3<r<1 / 2$, then $\partial q_{1}^{C C} / \partial r>0$; if $0<e \leq 5(b-c) / 2\left(3 r^{2}-8 r+2\right)$, then $\partial p_{i}^{C C} / \partial r \leq 0$; if $e>5(b-c) / 2\left(3 r^{2}-8 r+2\right)$, then

$$
\begin{aligned}
& \frac{\partial p_{i}^{C C}}{\partial r}>0, \frac{\partial \pi_{1}^{C C}}{\partial r}>0, \frac{\partial q_{2}^{C C}}{\partial r}=\frac{6 e r^{3}+3(b-}{\text { if } \quad} \\
& <e \leq \frac{\left(6 r^{3}-24 r^{2}+27 r-2\right)(b-c)}{-\left(18 r^{4}-58 r^{3}+45 r^{2}+12 r-8\right)} \text {, then } \frac{\partial \pi_{2}^{C C}}{\partial r} \leq 0 \text {, } \\
& \text { if } e>\left(6 r^{3}-24 r^{2}+27 r-2\right)(b-c) /-\left(18 r^{4}-58 r^{3}\right. \\
& \left.+45 r^{2}+12 r-8\right), \text { then } \partial \pi_{2}^{C C} / \partial r>0, \partial C S^{C C} / \partial r>0 \\
& \partial S W^{C C} / \partial r>0 .
\end{aligned}
$$

\section{Proof. See Appendix C}

Proposition 3 shows that, when both the leader and the follower implement SR, most of the equilibrium results are positively correlated with $e$; only the price and profit of University 1 and the profit of University 2 are uncorrelated with MS when the SR level is on a certain level $(r=1 / 2)$. In Model LC and Model FC, $e$ promotes the equilibrium results of the party implementing SR and suppresses those of the party failing to implement SR. When two universities implement SR, e exerts a positive influence in most cases because of competition, but the degree of influence varies from case to case.

The relationship between the output of University 1 and $r$ is more complex than that when only one university implements SR. In Model CC, there are three possible cases: both the SR level of University 1 and MS are low; the SR level of University 1 is low and MS is high; the University 1 is high. Except for the first case, the output and profit of University 1 are positively correlated with $r$. With the increase of $r$, the prices of both parties and the profit of University 2 first decrease and then increase. As the output of University 2, CS and SW are positively correlated with $r$. Therefore, when both the leader and the follower implement SR, and the MS is high, two universities, consumers, and the government have the motives to improve the SR level of universities. 
3.4. Model NN. Under Model NN, similar to Model CC, the equilibrium outputs can be described as

$$
q_{1}^{\mathrm{NN}}=\frac{b-c}{2}, q_{2}^{\mathrm{NN}}=\frac{b-c}{4} .
$$

Lemma 4. When neither the leader nor the follower implements $S R$, the equilibrium results are as follows:

$$
\pi_{1}^{\mathrm{NN}}=\frac{(b-c)^{2}}{8}, \pi_{2}^{\mathrm{NN}}=\frac{(b-c)^{2}}{16}, \mathrm{CS}^{\mathrm{NN}}=\frac{9(b-c)^{2}}{32}, \mathrm{SW}^{\mathrm{NN}}=\frac{15(b-c)^{2}}{32}
$$

In this scenario, the equilibrium results are not correlated with $e$ or $r$, but negatively correlated with market size (b) and marginal cost (c). Therefore, when neither the leader nor the follower implements SR, the following terms all increase with $b$ and decrease with the growth of $c$ : the output, price, and profit of each university, CS and SW.

3.5. Comparison. To ensure the meaningfulness of the above results, the parameter ranges must be limited to

$$
0<r<\min \left\{\frac{b-c}{b-c+2 e}, \frac{1}{2}\right\} \text { and } 0<e<\frac{(1-r)(b-c)}{2 r} \text {. }
$$

Corollary 1. Comparison of the profits of University 1: if

$$
0<e<\frac{\left(r^{2}+4 r+8+\sqrt{r^{4}-10 r^{3}+36 r^{2}-64 r+64}\right)(b-c)}{-8 r(r-2)},
$$

then $\pi_{1}^{N N}>\pi_{1}^{L C}>\pi_{1}^{F C}>\pi_{1}^{C C}$; if

$$
\begin{aligned}
& \frac{\left(r^{2}+4 r+8+\sqrt{r^{4}-10 r^{3}+36 r^{2}-64 r+64}\right)(b-c)}{-8 r(r-2)} \\
& <e<\frac{\left[\sqrt{\left(41 r^{4}-168 r^{3}+272 r^{2}-224 r+64\right)(4-3 r)^{2}(4-r)^{2}}+4 r^{5}-51 r^{4}+198 r^{3}-360 r^{2}+352 r-128\right](b-c)}{-2 r^{2}\left(2 r^{4}-21 r^{3}+69 r^{2}-88 r+48\right)},
\end{aligned}
$$

then $\pi_{1}^{L C}>\pi_{1}^{N N}>\pi_{1}^{F C}>\pi_{1}^{C C}$; if

$$
\begin{aligned}
& \frac{\left[\sqrt{\left(41 r^{4}-168 r^{3}+272 r^{2}-224 r+64\right)(4-3 r)^{2}(4-r)^{2}}+4 r^{5}-51 r^{4}+198 r^{3}-360 r^{2}+352 r-128\right](b-c)}{-2 r^{2}\left(2 r^{4}-21 r^{3}+69 r^{2}-88 r+48\right)} \\
& <e<\frac{\left[8 r^{3}-20 r^{2}+24 r-8+\sqrt{-36 r^{5}+186 r^{4}-412 r^{3}+484 r^{2}-288 r+64}\right](b-c)}{-4 r\left(2 r^{3}-5 r^{2}+6 r-2\right)}
\end{aligned}
$$

then $\pi_{1}^{L C}>\pi_{1}^{N N}>\pi_{1}^{C C}>\pi_{1}^{F C}$; if

$$
\frac{\left[8 r^{3}-20 r^{2}+24 r-8+\sqrt{-36 r^{5}+186 r^{4}-412 r^{3}+484 r^{2}-288 r+64}\right](b-c)}{-4 r\left(2 r^{3}-5 r^{2}+6 r-2\right)}<e<\frac{(1-r)(b-c)}{2 r},
$$


then $\pi_{1}^{L C}>\pi_{1}^{C C}>\pi_{1}^{N N}>\pi_{1}^{F C}$.

Comparison of the profits of University 2: if

$$
0<e<\frac{\left[-8 r^{3}+12 r^{2}+4 r-4+\sqrt{18 r^{5}-75 r^{4}+95 r^{3}-15 r^{2}-40 r+16}\right](b-c)}{4 r\left(2 r^{3}-3 r^{2}-r+1\right)},
$$

then $\pi_{1}^{N N}>\pi_{1}^{C C}>\pi_{1}^{F C}>\pi_{1}^{L C}$; if

$$
\frac{\left[-8 r^{3}+12 r^{2}+4 r-4+\sqrt{18 r^{5}-75 r^{4}+95 r^{3}-15 r^{2}-40 r+16}\right](b-c)}{4 r\left(2 r^{3}-3 r^{2}-r+1\right)}<e<\frac{3(b-c)}{4(3-r)}
$$

then $\pi_{1}^{C C}>\pi_{1}^{N N}>\pi_{1}^{F C}>\pi_{1}^{L C}$; if

$$
\frac{3(b-c)}{4(3-r)}<e<\frac{\left[-2 r^{5}+28 r^{4}-115 r^{3}+178 r^{2}-113 r+32-2 \sqrt{(2 r-1)\left(r^{2}-r-1\right)(4-r)^{2}(4-3 r)^{2}}\right](b-c)}{r\left(2 r^{5}-28 r^{4}+133 r^{3}-280 r^{2}+288 r-128\right)}
$$

then $\pi_{1}^{C C}>\pi_{1}^{F C}>\pi_{1}^{N N}>\pi_{1}^{L C}$; if

$$
\frac{\left[-2 r^{5}+28 r^{4}-115 r^{3}+178 r^{2}-113 r+32-2 \sqrt{(2 r-1)\left(r^{2}-r-1\right)(4-r)^{2}(4-3 r)^{2}}\right](b-c)}{r\left(2 r^{5}-28 r^{4}+133 r^{3}-280 r^{2}+288 r-128\right)}<e<\frac{(1-r)(b-c)}{2 r}
$$

then $\pi_{1}^{F C}>\pi_{1}^{C C}>\pi_{1}^{N N}>\pi_{1}^{L C} ; \quad C S^{C C}>C S^{L C}>C S^{F C}>C S^{N N}$; $S W^{C C}>S W^{L C}>S W^{F C}>S W^{N N}$.

Proof. See Appendix D

Assume $b=2, c=1$, and $r=0.1$. The comparison results are shown in Figures 1 and 2. The profits of universities are rather complex. There are four scenarios divided by MS. For University 1, when the competitor does not implement SR, if the MS is low $\left(0<e<\left(r^{2}+4 r+8+\right.\right.$ $\left.\left.\sqrt{r^{4}-10 r^{3}+36 r^{2}-64 r+64}\right)(b-c) /-8 r(r-2)\right)$, the optimal decision is not to implement SR; if MS reaches a certain level $\quad\left(e=\left(r^{2}+4 r+8+\sqrt{r^{4}-10 r^{3}+36 r^{2}-64 r+64}\right)\right.$ $(b-c) /-8 r(r-2))$, the optimal strategy is to implement SR. If the competitor implements SR, a high MS $\left(\left[\left[\sqrt{\left(41 r^{4}-168 r^{3}+272 r^{2}-224 r+64\right)(4-3 r)^{2}} \quad(4-r)^{2}\right.\right.\right.$ $\left.+4 r^{5}-51 r^{4}+198 r^{3}-360 r^{2}+352 r-128\right](b-c) /-2 r^{2}$ $\left(2 r^{4}-21 r^{3}+69 r^{2}-88 r+48\right)<e<\left[8 r^{3}-20 r^{2}+24 r-8+\right.$ $\left.\sqrt{-36 r^{5}+186 r^{4}-412 r^{3}+484 r^{2}}-288 r+64\right](b-c) /-4 r$ $\left.\left(2 r^{3}-5 r^{2}+6 r-2\right)\right)$ is the only situation that favors University 1 . For University 2, when the leader does not implement SR, if the MS is low $(0<e<$ $\left[-8 r^{3}+12 r^{2}+4 r-4+\sqrt{18 r^{5}-75 r^{4}+95 r^{3}-15 r^{2}}-40 r+\right.$ $\left.16](b-c) / 4 r\left(2 r^{3}-3 r^{2}-r+1\right)\right)$, the optimal decision is not to implement $\mathrm{SR}$; if $\mathrm{MS}$ reaches a certain level $\quad\left(e=\left[-2 r^{5}+28 r^{4}-115 r^{3}+178 r^{2}-113 r+32-2\right.\right.$ $\left.\sqrt{(2 r-1)\left(r^{2}-r-1\right)(4-r)^{2}(4-3 r)^{2}}\right](b-c) / r\left(2 r^{5}-28 r^{4}\right.$ $\left.\left.+133 r^{3}-280 r^{2}+288 r-128\right)\right)$, the follower should implement SR, whether the leader implements SR or not. The highest consumer surplus and social welfare exit when both the leader and the follower implement SR, followed in turn by when only the leader implements SR, when only the follower implements SR, and when neither the leader nor the follower implements SR. From the perspective of consumers and the government, the best situation is that two universities implement SR.

3.6. Optimal SR Level. Furthermore, this paper attempts to determine the optimal SR level.

\section{Corollary 2.}

(1) Under the maximization of profits, the optimal SR level can be determined as (see Table 1)

$r^{L C 1}=b-c / b-c+2 e ;$ if $0<e \leq 1 / 4(b-c)$, then $r^{F C 1}=0 ; \quad$ if $1 / 4(b-c)<e \leq 0.3847(b-c)$, then $r^{F C 1}=4 e-\sqrt{e(4 e+3 b-3 c)} / e ; \quad$ if $\quad 0.3847(b-c)$ 


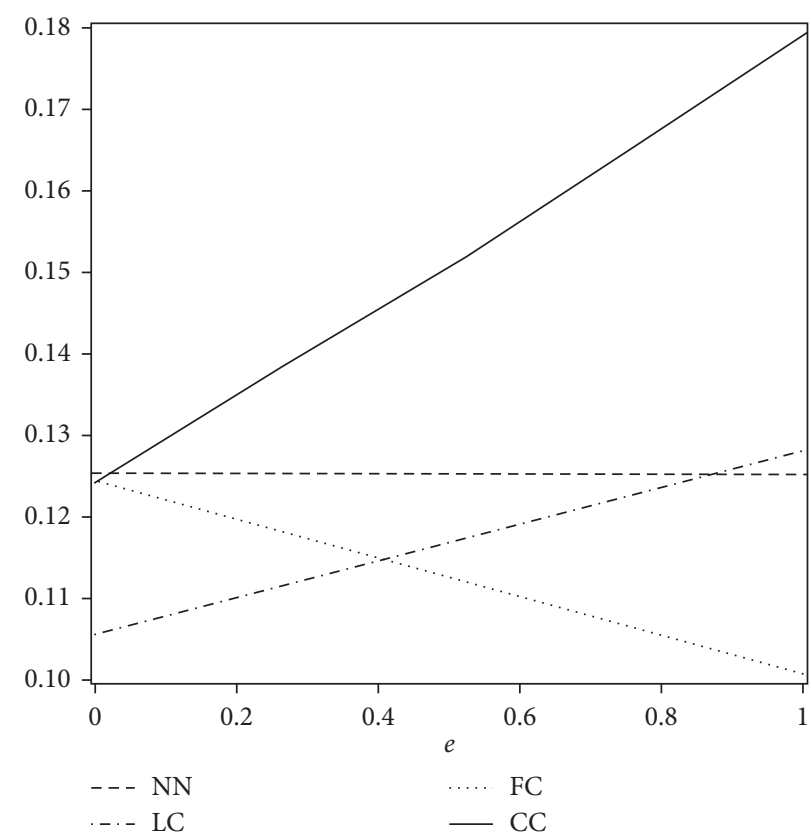

FIGURE 1: Comparison of the profits of University 1.

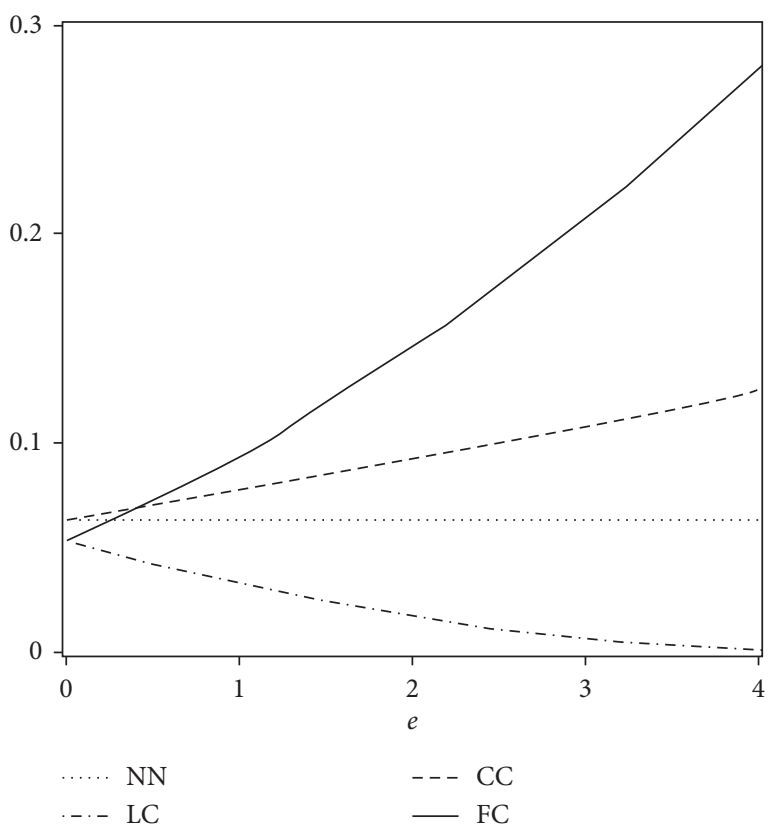

(a)

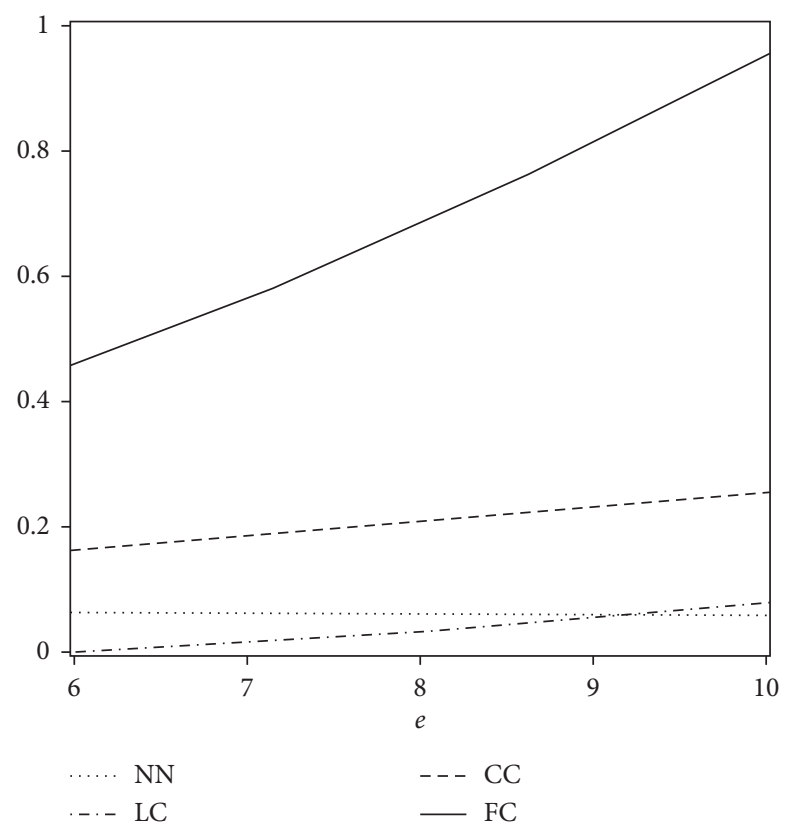

(b)

FIgURE 2: Comparison of the profits of University 2. 
TABLE 1: The optimal SR level.

\begin{tabular}{|c|c|c|c|}
\hline $\begin{array}{l}\text { Models } \\
\text { maximization }\end{array}$ & LC & $\mathrm{FC}$ & CC \\
\hline $\begin{array}{l}\text { Profits } \\
\text { maximization }\end{array}$ & $r^{\mathrm{LC} 1}=b-c / b-c+2 e$ & $\begin{array}{c}0<e \leq 1 / 4(b-c), r^{\mathrm{FC} 1}=0 \\
1 / 4(b-c)<e \leq 0.3847(b-c) \\
r^{\mathrm{FC} 1}=4 e-\sqrt{e(4 e+3 b-3 c)} / e \\
0.3847(b-c)<e<(1-r)(b-c) / 2 r \\
r^{\mathrm{FC} 1}=b-c / b-c+2 e\end{array}$ & $\begin{array}{c}r^{\mathrm{CC} 11}=1 / 2 \\
r^{\mathrm{CC} 12}=6(b-c)-58 e /-72 e-A / 2+1 / 2 \sqrt{B-D / A}\end{array}$ \\
\hline $\begin{array}{l}\text { Social welfare } \\
\text { maximization } \\
\text { Comparison }\end{array}$ & $\begin{array}{c}r^{\mathrm{LC} 2}=b-c / b-c+2 e \\
r^{\mathrm{LC} 1}=r^{\mathrm{LC} 2}\end{array}$ & $\begin{array}{c}r^{\mathrm{FC} 2}=b-c / b-c+e \\
r^{\mathrm{FC} 1}<r^{\mathrm{FC} 2}\end{array}$ & $\begin{array}{c}r^{\mathrm{CC} 21}=r^{\mathrm{CC} 22}=1 / 2 \\
r^{\mathrm{CC} 11}<r^{\mathrm{CC} 11}=r^{\mathrm{CC} 21}=r^{\mathrm{CC} 22}\end{array}$ \\
\hline
\end{tabular}

$<e<(1-r)(b-c) / 2 r$, then $r^{F C 1}=b-c / b-c+2 e ; \quad$ where

$r^{C C 11}=1 / 2$,

$r^{\mathrm{CC} 12}=\frac{6(b-c)-58 e}{-72 e}-\frac{A}{2}+\frac{1}{2} \sqrt{B-\frac{D}{A}}$,

$$
\begin{aligned}
& A=\sqrt{\frac{(6 b-6 c-58 e)^{2}}{1296 e^{2}}+\frac{F^{2}+16(b-c) F-30 e F+265 e^{2}+210(b-c) e+10(b-c)^{2}}{18 F e}}, \\
& B=\sqrt{\frac{(6 b-6 c-58 e)^{2}}{648 e^{2}}-\frac{F^{2}-32(b-c) F+60 e F+265 e^{2}+210(b-c) e+10(b-c)^{2}}{18 F e}}, \\
& D=\frac{[147 e+3(b-c)]\left[61 e^{2}+24(b-c) e+9(b-c-5)^{2}\right]}{-2916 e^{3}} \text { and } \\
& F=\left\{\begin{array}{c}
10 \sqrt{10} \sqrt{[3(b-c)+4 e]\left[\frac{1191 e^{5}}{2}+\frac{19045(b-c) e^{4}}{24}+\frac{3185(b-c)^{2} e^{3}}{6}+\frac{715(b-c)^{3} e^{2}}{3}+\frac{85(b-c)^{4} e}{3}+(b-c)^{5}\right]} \\
+100\left(b^{3}-c^{3}\right)+(-300 c+1650 e) b^{2}+\left(300 c^{2}-3300 c e+5825 e^{2}\right) b+1650 e c^{2}-5825 e^{2} c+5075 e^{3}
\end{array}\right.
\end{aligned} .
$$

(2) Under the maximization of social welfare, the optimal $S R$ level can be determined as (see Table 1)

$$
r^{\mathrm{LC} 2}=\frac{b-c}{b-c+2 e}, r^{\mathrm{FC} 2}=\frac{b-c}{b-c+e}, r^{\mathrm{CC} 21}=r^{\mathrm{CC} 22}=\frac{1}{2} .
$$

(3) The comparison results are (see Table 1) $r^{L C 1}=r^{L C 2}, r^{F C 1}<r^{F C 2}$, $r^{C C 11}<r^{C C 11}=r^{C C 21}=r^{C C 22}$.

Corollary 2 and Table 1 show that if University 1 determines the optimal SR level, it will bear the highest level of SR; whether the competitor implements SR or not, the optimal SR level is at the maximum critical value. However, if University 2 determines the optimal SR level, the situation will be more complicated. When the competitor does not implement SR, University 2 will select between three optimal SR levels according to $e$; when the competitor implements SR, University 2 selects the optimal SR level corresponding to the current MS. Under the principle of social welfare maximization, the optimal SR level determined by the government falls at the maximum critical value. When only the leader implements SR and both universities implement SR, the leader and the government have the same optimal SR level, and the optimal SR level of the follower is lower. Therefore, the government should encourage the leader to shoulder SR.

\section{Conclusions}

Considering SR and MS, this paper constructs a Stackelberg competition model for the education market and examines the influence of SR and MS on equilibrium results. Through analysis, the SR decisions of universities and the government are obtained, and the optimal SR level is determined for each scenario. The main conclusions are as follows.

First, MS $(e)$ influences equilibrium results. In Models LC and FC, $e$ promotes the output, price, and profit of the university implementing SR. In this case, the influence of $e$ depends on whether universities implement SR, rather than its competitive position. Therefore, as long as universities are 
willing to implement social responsibility, they will benefit from the market's influence. In Model CC, $e$ exerts a positive impact on the equilibrium results of the two universities in most cases, but the degree of influence varies from case to case. In addition, both CS and SW increase with $e$. Whether it is for the university implementing SR, consumers, or the government, the growing market recognition of $\mathrm{SR}$ is conductive. The university can win more market recognition by stepping up the publicity of its SR implementation. The government could promote the social recognition of SR implementation through policy support and publicity. Therefore, universities and the government can also cooperate to create a good social atmosphere.

Second, the SR level $(r)$ of universities influences equilibrium results. In Model LC and Model FC, the higher the $r$ value, the lower the price and profit of the university failing to implement SR, and the higher the CS and SW. For the university implementing SR, however, the equilibrium results could increase or decrease. The specific change depends on $e$. Thus, universities need to take corresponding strategic actions according to the market environment. In Model CC, the situation is even more complex. There are three possible relationships between the leader's output and the SR level. If $e$ is sufficiently high, the two universities have the motives to improve their SR level. Hence, an important means to promote leaders to adopt high-level social responsibility is to increase the market's recognition of socially responsible behaviors.

Third, for universities, the strategic decisions on SR vary with the competition situations. For University 1, the optimal strategy could be neither party implement SR, and only it implements SR. If the competitor does not implement SR,
University 1 needs to determine whether to implement SR according to the $e$ value. For University 2, the optimal strategy could be neither party implement SR, both parties implement SR, and only it implements SR. If the opponent implements SR, the follower's optimal strategy is implementation. Therefore, the leader's behavior affects the follower' decision. Once $e$ surpasses a certain level, University 2 should choose to implement SR, whether the leader implements SR or not.

Fourth, the optimal SR level is associated with the decision-maker. If University 1 is the decision-maker, whether the competitor implements SR or not, it will bear the highest level of SR. This SR level is consistent with the optimal SR level derived by the government, in the pursuit of maximal social welfare. If University 2 is the decision-maker, it will choose according to the $e$ value, and the selected optimal SR level will be lower than that defined by the leader or government. If the government wants to promote SR implementation among universities, it should encourage the leader to implement the SR first.

For further studies, it would be important to examine the case that universities' position is determined by market competition. Besides, it would be also interesting to explore many universities but not only two universities to make conclusions more applicable to reality.

\section{Appendix}

\section{A. Proof of Proposition 1}

$$
\begin{gathered}
\frac{\partial q_{1}^{\mathrm{LC}}}{\partial e}=\frac{4 r}{4-r}>0, \frac{\partial p_{1}^{\mathrm{LC}}}{\partial e}=\frac{r(2-r)}{4-r}>0, \frac{\partial \pi_{1}^{\mathrm{LC}}}{\partial e}=\frac{-r\left[(b-c+8 e) r^{2}+4(b-c-4 e) r-8(b-c)\right]}{(4-r)^{2}}>0, \\
\frac{\partial q_{2}^{\mathrm{LC}}}{\partial e}=\frac{2 r}{r-4}<0, \frac{\partial p_{2}^{\mathrm{LC}}}{\partial e}=\frac{2 r}{r-4}<0, \frac{\partial \pi_{2}^{\mathrm{LC}}}{\partial e}=\frac{4[(b-c+2 e) r-b+c] r}{(4-r)^{2}}<0, \\
\frac{\partial \mathrm{CS}^{\mathrm{LC}}}{\partial e}=\frac{2 r(2 e r+3 b-3 c)}{(4-r)^{2}}>0, \frac{\partial \mathrm{SW}^{\mathrm{LC}}}{\partial e}=\frac{\left[2(b-c)(3 \lambda+2)-(b-c+8 e) r^{2}+4 e(\lambda+6) r\right] r}{(4-r)^{2}}>0, \\
\frac{\partial q_{1}^{\mathrm{LC}}}{\partial r}=\frac{2(3 b-3 c+8 e)}{(4-r)^{2}}>0, \frac{\partial p_{1}^{\mathrm{LC}}}{\partial r}=\frac{\left(r^{2}-8 r+8\right) e-3 b+3 c}{(4-r)^{2}},
\end{gathered}
$$

if $0<e<3(b-c) / r^{2}-8 r+12$, then $\partial p_{1}^{\mathrm{LC}} / \partial r<0$, if $3(b-c) / r^{2}-8 r+12<e<(1-r)(b-c) / 2 r$, then $\partial p_{1}^{\mathrm{LC}} / \partial r$ $>0$, 


$$
\begin{aligned}
\frac{\partial \pi_{1}^{\mathrm{LC}}}{\partial r} & =\frac{e(b-c+4 e) r^{3}-12 e(b-c+4 e) r^{2}-\left[9(b-c)^{2}+24(b-c) e-64 e^{2}\right] r+32 e(b-c)}{(4-r)^{3}}>0, \frac{\partial q_{2}^{\mathrm{LC}}}{\partial r}=\frac{-3 b+3 c-8 e}{(4-r)^{2}}<0, \\
\frac{\partial p_{2}^{\mathrm{LC}}}{\partial r} & =\frac{-3 b+3 c-8 e}{(4-r)^{2}}<0, \frac{\partial \pi_{2}^{\mathrm{LC}}}{\partial r}=\frac{2[3(b-c)+8 e][(b-c+2 e) r-b+c]}{(4-r)^{3}}<0, \frac{\partial \mathrm{CS} S^{\mathrm{LC}}}{\partial r}=\frac{(3 b-3 c+8 e)(2 e r+3 b-3 c))}{(4-r)^{3}}>0, \\
\frac{\partial \mathrm{SW}^{\mathrm{LC}}}{\partial r} & =\frac{4 r\left(r^{2}+4 \lambda-12 r+24\right) e^{2}+(b-c)\left[r^{3}-12 r^{2}+2(3 \lambda+2) r+8(3 \lambda+2)\right] e-3(b-c)^{2}(r-3 \lambda+2)}{(4-r)^{3}}>0,
\end{aligned}
$$

\section{B. Proof of Proposition 2}

$$
\begin{aligned}
\frac{\partial q_{1}^{\mathrm{FC}}}{\partial e} & =\frac{r(r-2)}{4-r}<0, \frac{\partial p_{1}^{\mathrm{FC}}}{\partial e}=\frac{r}{r-4}<0, \frac{\partial \pi_{1}^{\mathrm{FC}}}{\partial e}=\frac{[(b-c+e) r-b+c]\left[2(b-c)-(b-c)-(b-c-2 e) r-e r^{2}\right.}{8 r(2-r)}<0, \\
\frac{\partial q_{2}^{\mathrm{FC}}}{\partial e} & =\frac{r(3-r)}{4-r}>0, \frac{\partial \pi_{2}^{\mathrm{FC}}}{\partial e}=\frac{2\left[e r^{2}+(b-c) r-3 e r-b+c\right] r(r-3)}{(4-r)^{2}}>0, \frac{\partial \mathrm{CS}}{\partial e}=\frac{r(e r+3 b-3 c)}{(4-r)^{2}}>0, \\
\frac{\partial \mathrm{SW}^{\mathrm{FC}}}{\partial e} & =\frac{r\left\{2 e r^{3}+(b-c-14 e) r^{2}+[-6(b-c)+(\lambda+22) e] e+(3 \lambda+2)(b-c)\right\}}{(4-r)^{2}}>0, \frac{\partial p_{2}^{\mathrm{FC}}}{\partial e}=\frac{r(3-r)}{4-r} \\
& >0, \frac{\partial q_{1}^{\mathrm{FC}}}{\partial r}=\frac{\left(-r^{2}+8 r-8\right) e+6(b-c)}{(4-r)^{2}},
\end{aligned}
$$

if $0<e<6(b-c)-\left(r^{2}-8 r+8\right) e /(4-r)^{2}, \partial q_{1}^{\mathrm{FC}} / \partial r<0$, if

$$
\frac{6(b-c)-\left(r^{2}-8 r+8\right) e}{(4-r)^{2}}<e<\frac{(1-r)(b-c)}{r}, \frac{\partial q_{1}^{\mathrm{FC}}}{\partial r}>0, \frac{\partial p_{1}^{\mathrm{FC}}}{\partial r}=\frac{-3(b-c)-4 e}{(4-r)^{2}}<0, \frac{\partial q_{2}^{\mathrm{FC}}}{\partial r}=\frac{\left(r^{2}-8 r+12\right) e-3(b-c)}{(4-r)^{2}}
$$

if $0<e<3(b-c) / r^{2}-8 r+12, \partial q_{2}^{\mathrm{FC}} / \partial r<0$, if

$$
\frac{3(b-c)}{r^{2}-8 r+12}<e<\frac{(1-r)(b-c)}{r}, \frac{\partial q_{2}^{\mathrm{FC}}}{\partial r}>0, \frac{\partial p_{2}^{\mathrm{FC}}}{\partial r}=\frac{\left(r^{2}-8 r+12\right) e-3(b-c)}{(4-r)^{2}},
$$

if $0<e<3(b-c) / r^{2}-8 r+8$, then $\partial p_{2}^{\mathrm{FC}} / \partial r<0, \quad$ if $3(b-c) / r^{2}-8 r+12<e<(1-r)(b-c) / r$, then $\partial p_{2}^{\mathrm{FC}}$ $/ \partial r>0$,

$$
\begin{aligned}
\frac{\partial \pi_{1}^{\mathrm{FC}}}{\partial r} & =\frac{e(b-c+e) r^{3}-12 e(b-c+e) r^{2}-\left[9(b-c)^{2}-12(b-c) e-16 e^{2}\right] r-16 e(b-c)}{(4-r)^{3}}<0, \\
\frac{\partial \pi_{2}^{\mathrm{FC}}}{\partial r} & =\frac{2\left[-e r^{2}+8 e r+3(b-c)-12 e\right]\left[e r^{2}+(b-c-3 e) r-b+c\right]}{(4-r)^{3}}>0,
\end{aligned}
$$


if $0<e<3(b-c) / r^{2}-8 r+12$, then $\partial \pi_{2}^{\mathrm{FC}} / \partial r<0$; if $3(b-c) / r^{2}-8 r+12<e<(1-r)(b-c) / r$, then $\partial \pi_{2}^{\mathrm{FC}} / \partial r>0$,

$$
\begin{aligned}
& \frac{\partial \mathrm{CS}^{\mathrm{FC}}}{\partial r}=\frac{(3 b-3 c+4 e)(e r+3 b-3 c)}{(4-r)^{3}}>0 \\
& \frac{\partial \mathrm{SW}^{\mathrm{FC}}}{\partial r}=\frac{\left.r\left(2 r^{3}-23 r^{2}-4 \lambda+84 r-88\right) e^{2}+(b-c)\left[r^{3}-12 r^{2}+(-3 \lambda+46) r-4(3 \lambda+2)\right)\right] e+3(b-c)^{2}(r-3 \lambda+2)}{(4-r)^{3}}>0,
\end{aligned}
$$

\section{Proof of Proposition 3}

To ensure $\pi_{2}^{\mathrm{CC}} \geq 0$, then $0<r \leq 1 / 2$.

$$
\begin{gathered}
\frac{\partial q_{1}^{\mathrm{CC}}}{\partial e}=\frac{\left(r^{2}-2 r+2\right) r}{4-3 r}>0, \frac{\partial p_{1}^{\mathrm{CC}}}{\partial e}=\frac{(1-2 r) r}{4-3 r} \geq 0, \frac{\partial \pi_{1}^{\mathrm{CC}}}{\partial e}=\frac{-2\left(r^{2}-2 r+2\right) r(e r+b-c)(2 r-1)}{(4-3 r)^{2}} \geq 0, \frac{\partial q_{2}^{\mathrm{CC}}}{\partial e}=\frac{-\left(r^{2}-r-1\right) r}{4-3 r}>0, \\
\frac{\partial p_{2}^{\mathrm{CC}}}{\partial e}=\frac{(1-2 r) r}{4-3 r} \geq 0, \frac{\partial \pi_{2}^{\mathrm{CC}}}{\partial e}=\frac{2\left(r^{2}-2 r+2\right) r(1-2 r)(e r+b-c)}{(4-3 r)^{2}} \geq 0, \frac{\partial \mathrm{CS}^{\mathrm{CC}}}{\partial e}=\frac{r(e r+3 b-3 c)(3-r)^{2}}{(4-3 r)^{2}}>0, \\
\frac{\partial \mathrm{SW}^{\mathrm{CC}}}{\partial e}=\frac{[(4+\lambda) r-3 \lambda-2] r(r-3)(e r+b-c)}{(4-3 r)^{2}}>0, \frac{\partial q_{1}^{\mathrm{CC}}}{\partial r}=\frac{-6 e r^{3}-3 e(b-c-6 e) r^{2}-8(b-c-2 e) r-2(b-c-4 e)}{(4-3 r)^{2}},
\end{gathered}
$$

if $\quad 0<r \leq 4-\sqrt{10} / 3$ and $0<e \leq\left(3 r^{2}-8 r+2\right)(b-c)$ $/ 2\left(4-8 r+9 r^{2}-3 r^{3}\right)$, then $\partial q_{1}^{\mathrm{CC}} / \partial r \leq 0$, if $0<r \leq 4-\sqrt{10} / 3$ and $e>\left(3 r^{2}-8 r+2\right)(b-c) / 2\left(4-8 r+9 r^{2}-3 r^{3}\right)$, then $\partial q_{1}^{\mathrm{CC}} / \partial r>0$, if $4-\sqrt{10} / 3<r<1 / 2$, then $\partial q_{1}^{\mathrm{CC}} / \partial r>0$, $\partial p_{1}^{\mathrm{CC}} / \partial r=2\left(3 r^{2}-8 r+2\right) e-5(b-c) /(4-3 r)^{2}$, if $0<e \leq 5$ $(b-c) / 2\left(3 r^{2}-8 r+2\right)$, then $\partial p_{1}^{\mathrm{CC}} / \partial r \leq 0, \quad$ if $e>5$ $(b-c) / 2\left(3 r^{2}-8 r+2\right)$, then $\partial p_{1}^{\mathrm{CC}} / \partial r>0$,

$$
\begin{aligned}
& \frac{\partial \pi_{1}^{\mathrm{CC}}}{\partial r}=\frac{e(b-c+4 e) r^{3}-12 e(b-c+4 e) r^{2}-\left[9(b-c)^{2}-24(b-c) e-64 e^{2}\right] r-32 e(b-c)}{(4-3 r)^{3}}>0 \\
& \frac{\partial q_{2}^{\mathrm{CC}}}{\partial r}=\frac{6 e r^{3}+3(b-c-5 e) r^{2}-8(b-c-e) r+7(b-c)+4 e}{4-3 r}>0 \\
& \frac{\partial \pi_{2}^{\mathrm{CC}}}{\partial r}=\frac{\left[18 e r^{4}+2(3 b-3 c-29 e) r^{3}+3(-8 b+8 c+15 e) r^{2}+3(9 b-9 c+4 e) r-2(b-c+4 e)\right](e r+b-c)}{(4-3 r)^{3}}
\end{aligned}
$$

if $0<e<\left(6 r^{3}-24 r^{2}+27 r-2\right)(b-c) /-\left(18 r^{4}-58 r^{3}+45 r^{2} \quad-2\right)(b-c) /-\left(18 r^{4}-58 r^{3}+45 r^{2}+12 r-8\right)$, then $\partial \pi_{2}^{\mathrm{CC}} / \partial r$ $+12 r-8)$, then $\partial \pi_{2}^{\mathrm{CC}} / \partial r \leq 0$, if $e>\left(6 r^{3}-24 r^{2}+27 r \quad>0\right.$, 


$$
\begin{aligned}
& \frac{\partial \mathrm{CS}^{\mathrm{CC}}}{\partial r}=\frac{\left(3 e r^{2}-8 e r+5 b-5 c+12 e\right)(3-r)(e r+b-c)}{(4-3 r)^{3}}>0, \\
& \frac{\partial \mathrm{SW}^{\mathrm{CC}}}{\partial r}=\frac{-\left\{3(\lambda+4) e r^{3}-(17 \lambda+53) e r^{2}+[(36 \lambda+84) e+5(\lambda+1)(b-c)] r-12(3 \lambda+2) e-5(b-c)(3 \lambda-2)\right\}(e r+b-c)}{(4-3 r)^{3}}>0 .
\end{aligned}
$$

\section{Proof of Corollary 1}

$$
\begin{aligned}
& \pi_{1}^{\mathrm{LC}}-\pi_{1}^{\mathrm{FC}}=\frac{3 e r(e r+2 b-2 c)(2-r)}{(4-r)^{2}}>0, \\
& \pi_{1}^{\mathrm{LC}}-\pi_{1}^{\mathrm{CC}}=\frac{\left[b-c-(b-c-2 e) r-e r^{2}\right][(b-c+4 e) r+2(b-c)](4-3 r)^{2}-(e r+b-c)^{2}\left(r^{2}-2 r+2\right)(2 r-1)(4-r)^{2}}{(4-r)^{2}(4-3 r)^{2}}>0, \\
& \pi_{1}^{\mathrm{LC}}-\pi_{1}^{\mathrm{NN}}=\frac{8 e(b-c+4 e) r^{2}+\left[-64 e^{2}+32(b-c) e+9(b-c)^{2}\right] r-64 e(b-c)}{-8(4-r)^{2}},
\end{aligned}
$$

if then $\pi_{1}^{\mathrm{LC}}-\pi_{1}^{\mathrm{NN}}<0$; if

$$
0<e<\frac{\left(r^{2}+4 r+8+\sqrt{r^{4}-10 r^{3}+36 r^{2}-64 r+64}\right)(b-c)}{-8 r(r-2)},
$$

$$
\frac{\left(r^{2}+4 r+8+\sqrt{r^{4}-10 r^{3}+36 r^{2}-64 r+64}\right)(b-c)}{-8 r(r-2)}<e<\frac{(1-r)(b-c)}{2 r},
$$

then $\pi_{1}^{\mathrm{LC}}-\pi_{1}^{\mathrm{NN}}>0$.

$$
\pi_{1}^{\mathrm{FC}}-\pi_{1}^{\mathrm{CC}}=\frac{\left[2(b-c)-(b-c-2 e) r-e r^{2}\right][(b-c+e) r-(b-c)](4-3 r)^{2}-(e r+b-c)^{2}\left(r^{2}-2 r+2\right)(2 r-1)(4-r)^{2}}{(4-r)^{2}(4-3 r)^{2}},
$$

if

$$
0<e<\frac{\left[4 r^{5}-51 r^{4}+198 r^{3}-360 r^{2}+352 r-128+\sqrt{\left(41 r^{4}-168 r^{3}+272 r^{2}-224 r+64\right)(4-3 r)^{2}(4-r)^{2}}\right](b-c)}{-2 r^{2}\left(2 r^{4}-21 r^{3}+69 r^{2}-88 r+48\right)},
$$


then $\pi_{1}^{\mathrm{FC}}-\pi_{1}^{\mathrm{CC}}>0$; if

$$
\frac{\left[4 r^{5}-51 r^{4}+198 r^{3}-360 r^{2}+352 r-128+\sqrt{\left(41 r^{4}-168 r^{3}+272 r^{2}-224 r+64\right)(4-3 r)^{2}(4-r)^{2}}\right](b-c)}{-2 r^{2}\left(2 r^{4}-21 r^{3}+69 r^{2}-88 r+48\right)}<e<\frac{(1-r)(b-c)}{2 r},
$$

then $\pi_{1}^{\mathrm{FC}}-\pi_{1}^{\mathrm{CC}}<0$;

$$
\begin{aligned}
& \pi_{1}^{\mathrm{FC}}-\pi_{1}^{\mathrm{NN}}=\frac{8\left[2(b-c)-(b-c-2 e) r-e r^{2}\right][(b-c+e) r-(b-c)]-(b-c)^{2}(4-r)^{2}}{8(4-r)^{2}}<0, \\
& \pi_{1}^{\mathrm{CC}}-\pi_{1}^{\mathrm{NN}}=\frac{8(e r+b-c)^{2}\left(r^{2}-2 r+2\right)(2 r-1)-(b-c)^{2}(4-3 r)^{2}}{8(4-3 r)^{2}},
\end{aligned}
$$

if

$$
0<e<\frac{\left[8 r^{3}-20 r^{2}+24 r-8+\sqrt{-36 r^{5}+186 r^{4}-412 r^{3}+484 r^{2}-288 r+64}\right](b-c)}{-4 r\left(2 r^{3}-5 r^{2}+6 r-2\right)},
$$

then $\pi_{1}^{\mathrm{CC}}-\pi_{1}^{\mathrm{NN}}<0$.

$$
\frac{\left[8 r^{3}-20 r^{2}+24 r-8+\sqrt{-36 r^{5}+186 r^{4}-412 r^{3}+484 r^{2}-288 r+64}\right](b-c)}{-4 r\left(2 r^{3}-5 r^{2}+6 r-2\right)}<e<\frac{(1-r)(b-c)}{2 r},
$$

then $\pi_{1}^{\mathrm{CC}}-\pi_{1}^{\mathrm{NN}}>0$; if

$$
\begin{aligned}
& \pi_{2}^{\mathrm{LC}}-\pi_{2}^{\mathrm{FC}}=\frac{(e r+2 b-2 c)(5-r)(1-r) e}{-(4-r)^{2}}<0, \\
& \pi_{2}^{\mathrm{LC}}-\pi_{2}^{\mathrm{CC}}=\frac{[(b-c+2 e) r-b+c]^{2}(4-3 r)^{2}-\left(r^{2}-r-1\right)(2 r-1)(e r+b-c)^{2}(4-r)^{2}}{(4-r)^{2}(4-3 r)^{2}}<0, \\
& \pi_{2}^{\mathrm{LC}}-\pi_{2}^{\mathrm{NN}}=\frac{16[(b-c+2 e) r-b+c]^{2}-(b-c)^{2}(4-r)^{2}}{16(4-r)^{2}}<0, \\
& \pi_{2}^{\mathrm{FC}}-\pi_{2}^{\mathrm{CC}}=\frac{\left[e r^{2}+(b-c-3 e) r-b+c\right]^{2}(4-3 r)^{2}-\left(r^{2}-r-1\right)(2 r-1)(e r+b-c)^{2}(4-r)^{2}}{(4-r)^{2}(4-3 r)^{2}},
\end{aligned}
$$

if 


$$
0<e<\frac{\left[-2 r^{5}+28 r^{4}-115 r^{3}+178 r^{2}-113 r+32-2 \sqrt{(2 r-1)\left(r^{2}-r-1\right)(4-r)^{2}(4-3 r)^{2}}\right](b-c)}{r\left(2 r^{5}-28 r^{4}+133 r^{3}-280 r^{2}+288 r-128\right)},
$$

then $\pi_{2}^{\mathrm{FC}}-\pi_{2}^{\mathrm{CC}}<0$; if

$$
\frac{\left[-2 r^{5}+28 r^{4}-115 r^{3}+178 r^{2}-113 r+32-2 \sqrt{(2 r-1)\left(r^{2}-r-1\right)(4-r)^{2}(4-3 r)^{2}}\right](b-c)}{r\left(2 r^{5}-28 r^{4}+133 r^{3}-280 r^{2}+288 r-128\right)}<e<\frac{(1-r)(b-c)}{2 r},
$$

then $\pi_{2}^{\mathrm{FC}}-\pi_{2}^{\mathrm{CC}}>0$,

$$
\pi_{2}^{\mathrm{FC}}-\pi_{2}^{\mathrm{NN}}=\frac{16\left[e r^{2}+(b-c-3 e) r-b+c\right]^{2}-(b-c)^{2}(4-r)^{2}}{16(4-r)^{2}},
$$

if $0<e<3(b-c) / 4(3-r)$, then $\pi_{2}^{\mathrm{FC}}-\pi_{2}^{\mathrm{NN}}<0$; if $3(b-c) / 4(3-r)<e<(1-r)(b-c) / 2 r$, then $\pi_{2}^{\mathrm{FC}}-\pi_{2}^{\mathrm{NN}}>0$,

$$
\pi_{2}^{\mathrm{CC}}-\pi_{2}^{\mathrm{NN}}=\frac{16\left(r^{2}-r-1\right)(2 r-1)(e r+b-c)^{2}-(b-c)^{2}(4-3 r)^{2}}{16(4-3 r)^{2}},
$$

if

$$
0<e<\frac{\left[-8 r^{3}+12 r^{2}+4 r-4+\sqrt{18 r^{5}-75 r^{4}+95 r^{3}-15 r^{2}-40 r+16}\right](b-c)}{4 r\left(2 r^{3}-3 r^{2}-r+1\right)} \text {, then } \pi_{2}^{\mathrm{CC}}-\pi_{2}^{\mathrm{NN}}<0,
$$

if

$$
\frac{\left[-8 r^{3}+12 r^{2}+4 r-4+\sqrt{18 r^{5}-75 r^{4}+95 r^{3}-15 r^{2}-40 r+16}\right](b-c)}{4 r\left(2 r^{3}-3 r^{2}-r+1\right)}<e<\frac{(1-r)(b-c)}{2 r},
$$

then $\pi_{2}^{\mathrm{CC}}-\pi_{2}^{\mathrm{NN}}>0$, 


$$
\begin{aligned}
& \mathrm{CS}^{\mathrm{LC}}-\mathrm{CS}^{\mathrm{FC}}=\frac{3 e r(e r+b-c)}{2(4-r)^{2}}>0, \mathrm{CS}^{\mathrm{LC}}-\mathrm{CS}^{\mathrm{NN}}=\frac{16(2 e r+3 b-3 c)^{2}-9(b-c)^{2}(4-r)^{2}}{32(4-r)^{2}}>0, \mathrm{CS}^{\mathrm{LC}}-\mathrm{CS}^{\mathrm{CC}} \\
& =\frac{(2 e r+3 b-3 c)^{2}(4-3 r)^{2}-(e r+3 b-3 c)^{2}(4-r)^{2}}{2(4-r)^{2}(4-3 r)^{2}}<0 \text {, } \\
& \mathrm{CS}^{\mathrm{FC}}-\mathrm{CS}^{\mathrm{CC}}=\frac{(e r+3 b-3 c)^{2}(4-3 r)^{2}-(e r+b-c)^{2}(r-3)^{2}(4-r)^{2}}{2(4-r)^{2}(4-3 r)^{2}}<0, \mathrm{CS}^{\mathrm{FC}}-\mathrm{CS}^{\mathrm{NN}} \\
& =\frac{16(e r+3 b-3 c)^{2}-9(b-c)^{2}(4-r)^{2}}{32(4-r)^{2}}>0, \\
& \mathrm{SW}^{\mathrm{LC}}-\mathrm{SW}^{\mathrm{FC}}=\frac{\left(-2 r^{2}+3 \lambda+6 r+2\right)(e r+2 b-2 c) e}{2(4-r)^{2}}>0, \mathrm{SW}^{\mathrm{LC}}-\mathrm{SW}^{\mathrm{CC}} \\
& \left\{-2 e(b-c+4 e) r^{3}+4 e^{2}(\lambda+6) r^{2}-2(b-c)[3(b-c)-2(3 \lambda+2) e] r+3(b-c)^{2}(3 \lambda+2)\right\}(4-3 r)^{2} \\
& =\frac{-(e r+b-c)^{2}(r-3)[(\lambda+4) r-3 \lambda-2](4-r)^{2}}{2(4-r)^{2}(4-3 r)^{2}}<0, \\
& \mathrm{SW}^{\mathrm{LC}}-\mathrm{SW}^{\mathrm{NN}}=\frac{16\left\{-2 e(b-c+4 e) r^{3}+4 e^{2}(\lambda+6) r^{2}-2(b-c)[3(b-c)-2(3 \lambda+2) e] r+3(b-c)^{2}(3 \lambda+2)\right\}-15(b-c)^{2}(4-r)^{2}}{32(4-r)^{2}}>0, \\
& \mathrm{SW}^{\mathrm{FC}}-\mathrm{SW}^{\mathrm{CC}}=\frac{\left\{\begin{array}{c}
2 e^{2} r^{4}+2 e(b-c-7 e) r^{3}-4[-(\lambda+22)+12(b-c)] e r^{2}- \\
2(b-c) r[3(b-c)+(3 \lambda+2) e] r+3(b-c)^{2}(3 \lambda+2)
\end{array}\right\}(4-3 r)^{2}-(e r+b-c)^{2}(r-3)[(\lambda+4) r-3 \lambda-2](4-r)^{2}}{2(4-r)^{2}}<0, \\
& \mathrm{SW}^{\mathrm{FC}}-\mathrm{SW}^{\mathrm{NN}}=\frac{16\left\{\begin{array}{c}
2 e^{2} r^{4}+2 e(b-c-7 e) r^{3}-4[-(\lambda+22)+12(b-c)] e r^{2}- \\
2(b-c) r[3(b-c)+(3 \lambda+2) e] r+3(b-c)^{2}(3 \lambda+2)
\end{array}\right\}-15(b-c)^{2}(4-r)^{2}}{2(4-r)^{2}}>0, \\
& \mathrm{SW}^{\mathrm{CC}}-\mathrm{SW}^{\mathrm{NN}}=\frac{16(e r+b-c)^{2}(r-3)[(\lambda+4) r-3 \lambda-2]-15(b-c)^{2}(4-3 r)^{2}}{2(4-3 r)^{2}}>0 .
\end{aligned}
$$

\section{Data Availability}

The data used to support the findings of this study are available from the corresponding author upon request.

\section{Conflicts of Interest}

The authors declare that they have no conflicts of interest.

\section{Acknowledgments}

This work was supported by the Education Department Project of Jilin Province (grant number: JJKH20211238 SK), Major Project of Philosophy and Social Sciences Key Research Base of Jilin University (grant number: 2020XXJD13), Undergraduate Teaching Reform Research Project of Jilin University (grant number: 2021XZC022), MOE Project of Key Research Institute of Humanities and Social Sciences, and Fundamental Research Funds for the Central Universities (grant number: N2123006).

\section{References}

[1] L. P. Amaral, N. Martins, and J. B. Gouveia, "Quest for a sustainable university: a review," International Journal of Sustainability in Higher Education, vol. 16, no. 2, pp. 155-172, 2015.

[2] F. Findler, N. Schönherr, R. Lozano, D. Reider, and A. Martinuzzi, "The impacts of higher education institutions on sustainable development," International Journal of Sustainability in Higher Education, vol. 20, no. 1, pp. 23-38, 2019.

[3] J. Chen, B. Xu, Y. Xiao, and C. Sun, "The impacts and decision of community-friendly corporate social responsibility based on the duopoly model," Revista de Cercetare si Interventie Sociala, vol. 73, pp. 215-237, 2021.

[4] L. P. Babich, W. J. Bicknell, L. Culpepper, and B. W. Jack, "Social responsibility, international development, and institutional commitment: lessons from the boston university experience," Academic Medicine, vol. 83, no. 2, pp. 143-147, 2008.

[5] C. Boelen and B. Woollard, "Social accountability and accreditation: a new frontier for educational institutions," Medical Education, vol. 43, no. 9, pp. 887-894, 2009. 
[6] C. Boelen and R. Woollard, "Social accountability: the extra leap to excellence for educational institutions," Medical Teacher, vol. 33, no. 8, pp. 614-619, 2011.

[7] B. Woollard and C. Boelen, "Seeking impact of medical schools on health: meeting the challenges of social accountability," Medical Education, vol. 46, no. 1, pp. 21-27, 2012.

[8] J. Moon and M. Orlitzky, "Corporate social responsibility and sustainability education: a trans-Atlantic comparison," Journal of Management \& Organization, vol. 17, no. 5, pp. 583-603, 2011.

[9] M. Nejati, A. Shafaei, Y. Salamzadeh, and M. Daraei, "Corporate social responsibility and universities: a study of top 10 world Universities' websites," African Journal of Business Management, vol. 5, no. 2, pp. 440-447, 2011.

[10] A. M. Dima, S. Vasilache, V. Ghinea, and S. Agoston, "A model of academic social responsibility," Transylvanian Review of Administrative Sciences, vol. 9, no. 38E, pp. 23-43, 2013.

[11] R. G. Sánchez, M. P. R Bolívar, and A. M. López-Hernández, "Online disclosure of university social responsibility: a comparative study of public and private US universities," Environmental Education Research, vol. 19, no. 6, pp. 709-746, 2013.

[12] K. F. Latif, "The development and validation of stakeholderbased scale for measuring university social responsibility (USR)," Social Indicators Research, vol. 140, no. 2, pp. 511-547, 2018.

[13] W. Ventres, C. Boelen, and C. Haq, “Time for action: key considerations for implementing social accountability in the education of health professionals," Advances in Health Sciences Education, vol. 23, no. 4, pp. 853-862, 2018.

[14] A. M. Aleixo, S. Leal, and U. M. Azeiteiro, "Conceptualization of sustainable higher education institutions, roles, barriers, and challenges for sustainability: an exploratory study in Portugal," Journal of Cleaner Production, vol. 172, pp. 1664-1673, 2018.

[15] C. S. Hayter and D. R. Cahoy, "Toward a strategic view of higher education social responsibilities: a dynamic capabilities approach," Strategic Organization, vol. 16, no. 1, pp. 12-34, 2018.

[16] A. Galvão, L. Mendes, C. Marques, and C. Mascarenhas, "Factors influencing students' corporate social responsibility orientation in higher education," Journal of Cleaner Production, vol. 215, pp. 290-304, 2019.

[17] N. Ayala-Rodríguez, I. Barreto, G. R. Ossandón, A. Castro, and S. Moreno, "Social transcultural representations about the concept of university social responsibility," Studies in Higher Education, vol. 44, no. 2, pp. 245-259, 2019.

[18] A. M. Aleixo, U. Azeiteiro, and S. Leal, "The implementation of sustainability practices in Portuguese higher education institutions," International Journal of Sustainability in Higher Education, vol. 19, no. 1, pp. 146-178, 2018.

[19] L. P. Symaco and M. Y. Tee, "Social responsibility and engagement in higher education: case of the ASEAN," International Journal of Educational Development, vol. 66, pp. 184-192, 2019.

[20] M. H. Binsawad, "Corporate social responsibility in higher education: a PLS-SEM neural network approach," IEEE Access, vol. 8, pp. 29125-29131, 2020.

[21] S. Castro-González, B. Bande, P. Fernández-Ferírn, and T. Kimura, "Corporate social responsibility and consumer advocacy behaviors: the importance of emotions and moral virtues," Journal of Cleaner Production, vol. 231, pp. 846-855, 2019.
[22] L. Xu, X. Fan, and W. Luan, "Strategic corporate social responsibility of high-speed rail in China," China Economic Review, vol. 62, Article ID 101499, 2020.

[23] J. Chen, X. Xie, L. Liu, and R. Liu, "Externality, product differentiation and social welfare in the education market," Transformations in Business \& Economics, vol. 19, no. 3c, pp. 522-541, 2020.

[24] J. Chen, C. Sun, J. Liu, and Y. Huo, "The optimal level of corporate social responsibility based on the duopoly model," Managerial and Decision Economics, vol. 42, no. 1, pp. 177-184, 2021.

[25] Z. Liu, T. D. Anderson, and J. M. Cruz, "Consumer environmental awareness and competition in two-stage supply chains," European Journal of Operational Research, vol. 218, no. 3, pp. 602-613, 2012.

[26] J. Chen, J. Liu, and J. Qin, "Corporate social responsibility and capacity selection," Transformations in Business \& Economics, vol. 18, no. 3C, pp. 530-545, 2019.

[27] J. Chen, X. Wang, and J. Liu, "Corporate social responsibility and capacity sharing in a duopoly model," Applied Economics Letters, vol. 28, no. 6, pp. 512-517, 2021.

[28] J. Chen, C. Sun, and J. Liu, "Corporate social responsibility, consumer sensitivity, and overcapacity," Managerial and Decision Economics, Article ID e3401, 2021. 